\title{
Renewable Energy and Sustainable Development
}

\author{
Ruojue Lin ${ }^{1}$, Jingzheng Ren ${ }^{1}$ \\ ${ }^{1}$ Department of Industrial and Systems Engineering, \\ The Hong Kong Polytechnic University, \\ Hong Kong Special Administrative Region, China \\ Email: rachel.rj.lin@connect.polyu.hk
}

jzhren@polyu.edu.hk

\begin{abstract}
:
As the contradiction between human development and environmental maintenance is increasingly prominent, sustainability has become a significantly important goal for future development. The renewable energy plays an essential role in the achievement of sustainable development, since it is relatively cleaner comparing with fossil fuels. The renewable energy has the advantages that it has fewer negative impacts on the environment than fossil fuels, so it is beneficial in improving the environment, increasing the diversity of fuels, ensuring stable energy supply, and promoting regional economic development. To improve the sustainability and development of renewable energy, countries worldwide set up goals and implemented relative regulations and policies. This keynote paper firstly introduced sustainable development; subsequently, summarized the roles of renewable energy on sustainable development; then, had an overview of the achievements on sustainable development and renewable energy; after this, investigated the barriers and in sighted; and concluded this paper. The results reveal that there is still a far way to go before all Sustainability Development Goals (SDGs) will be finally achieved although many progresses of sustainability and renewable energy development in technological, economic, environmental and social aspects have been made during the past 20 years with the efforts of all countries.
\end{abstract}

Keywords: Renewable energy, sustainable development, sustainability

\section{Sustainable development}

As the contradiction between human development and environmental maintenance is increasingly prominent, whether limited natural resources would meet the material needs and living needs of the growing population become a problem [1]. Due to the limitation of natural resources, the production of food, necessities and other products is expected to be restricted one day in the future. Insufficient amount of resources will inevitably cause the stagnation of economic growth, the allocation problem of social resources and the tension of social relations [2]. Also, the deterioration of land resources and environmental conditions limits the scope of human activities and living standards [3]. Therefore, endless production and consumption will inevitably lead to irreconcilable contradictions and serious consequences. When these problems were widely discussed and the solutions were attempted, the concept of sustainable development was put forward and received more attentions.

Sustainable development refers to a development model that can be endlessly used with limited resources. The term "sustainable development" uses the definition of sustainable development that has been most frequently cited by the Brundtland Commission: "a development model that can meet our needs today without compromising future generations." [4]. During the development process, the definition is constantly refined and updated. The current mainstream concept of sustainable development can be explained environmental, economic and social aspects. Environmental speaking, we shall minimize damage to the environment, including rational allocation and planned use of limited resources and reduction of pollutant emissions. In terms of society, some human physical and mental needs should be met for sustainable development, such as work needs, family security, comfort living environment, and human health. In the economic aspect, only those activities that could make profits could last for long and achieve sustainability.

In the process of continuous development, sustainable development is recognized as the joint efforts of all mankind. Therefore, the United Nations released eight Millennium Development Goals (DMGs) in 2000 [5], including "extreme poverty and hunger eradication, universal primary education achievement, gender equality and empower women promotion, child mortality reduction, maternal health improvement, combating HIVIAIDS , malaria, and other diseases, environmental sustainability, and a global partnership for development" [5]. Certain DMGs have been achieved during 2000-2015, but a more detailed goals should be clarified.

Therefore, the goals for sustainable development were adjusted and extended to 17 goals as known as Sustainable Development Goals (SDGs) in 2015 [6]. The scope and definition are broader and clearer, so that all 
countries have clear goals for common development in the next 15 years. The revised SDGs include "no poverty, zero hunger, good health and well-being, quality education, gender equality, clean water and sanitation, affordable and clean energy, decent work and economic growth, industry, innovation, and infrastructure, reducing inequality, sustainable cities and communities, responsible consumption and production, climate action, life below water, life on land, peace, justice, and strong institutions, and partnerships for the goals" [6].

\section{Renewable energy}

Among all efforts made for promoting sustainable development, the renewable energy has played a significantly important role [7], [8]. Fossil fuels, such as coal, oil and natural gas, have been adopted as the major resources for energy generation for long in the history [9]. However, the use of fossil fuels causes land occupation, air pollution, and water pollution, which triggers damage to animals and plants, and climate change [10]. In addition, fossil energy is a non-renewable energy source, and its limited stocks on the earth will eventually be exhausted [11]. Renewable energy is naturally formed and can be repeatedly produced in the environment, such as solar energy, wind energy, ocean energy, biomass energy, water energy, and biomass energy [12]. Comparing with fossil fuels, renewable energies are clean energy sources that have fewer negative impacts on the environment than fossil fuels, and they are beneficial in improving the environment, increasing the diversity of fuels, ensuring stable energy supply, and promoting regional economic development [13]. In this case, the application of renewable energy has a direct positive effect on these SDGs including clean water and sanitation, affordable and clean energy, sustainable cities and communities, climate action, and life on land. In addition, the application of renewable energy also indirectly improves the development of the following goals by establishing more energy stations and providing more job opportunities: decent work and economic growth, gender equality, innovation, and infrastructure, no poverty, and zero hunger. Therefore, the development of renewable energy is an effective and important way to achieve sustainable development.

\section{Achievements}

After the concept of sustainable development has gained global recognition and attention, countries worldwide have formulated detailed goals at the national level according to their own development. The corresponding policies and supporting measures have been introduced and implemented to assist sustainable development. After 20 years, significant contributions for sustainable development in terms of technology, scope of application, economic benefit and environmental condition had been made [14]. The renewable energy has been widely applied and it accelerated environmental, economic, and social sustainability [15].

In recent years, the application of renewable energy has achieved technological innovation and improvement. Some relatively mature renewable energy power generation technologies, including hydropower, wind power and solar photovoltaic power generation, have been optimized and improved in energy generation efficiency, energy density and cost control [15]. The corresponding market has gradually matured and stabilized. 111 countries have designed and implemented feed-in tariffs (FIT) for renewable energy project. Some countries have gradually switched from FIT policies to more liberal and free market competition strategies, and there were more than 48 countries have replaced FIT by auction strategy [16]. It is expected that there will be more free market mechanisms explored in the future. In addition to the application of renewable energy mentioned above, other renewable energy sources such as geothermal energy, ocean energy have also been developed for power supply and heating in some areas, but they were not as popular as wind power, hydropower and photovoltaic energy [15]. In addition, many studies have also explored and studied the application of renewable energy in transportation, such as hydrogen batteries [17], solar cells [18], [19], and biomass fuel vehicles [20]. Furthermore, the optimization of the renewable energy supply chain, for example: energy storage [21], [22] and energy transmission [23], [24], have been widely studied.

The development of renewable energy has drawn attentions and has made great contributions with the efforts from all countries. Renewable energy targets had been adopted in 169 countries at the national or state level by the end of 2018, and the amount of annual investment rose from 177 billion USD in 2008 to 288.9 billion USD in 2018 [15]. In the past 20 years, the proportion of renewable energy power capacity has reached over $50 \%$ since 2015 [15]. The consumption of renewable energy has also reached $26 \%$ [25], which is a great achievement.

\section{Barriers and insights}

However, achievements of current sustainable development strategies are still far from that mentioned in the goal of global zero carbon emissions and other sustainable development goals. Following the current trend of $\mathrm{CO}_{2}$ emission and temperature change, it is difficult to achieve net zero carbon emission in 2030 [15], [26]. After analysis, the following obstacles exist in global sustainable development and some insights are provided. 
In the techno-economic aspect, the optimal energy system that best suits national conditions has not been determined by each country, but the amount of renewable energy investment that can be attracted is decreasing. While renewable energy technologies have room to upgrade, the energy mix of each country has not been optimized. Therefore, systematic and innovative studied should be conducted to develop and optimize an intelligent, mixed energy system.

Key development technologies suitable for the country should be analysed, evaluated, and selected according to national conditions, and the investment can be focused on cultivating key technologies due to the limited capital investment. The development of low-cost and accessible technologies for renewable energy provides more opportunities for countries to implement decarbonisation and to satisfy increasing energy needs. It can also provide more development possibilities for countries that do not have the advantages of existing renewable resources to reduce the impact of energy price fluctuations in other countries, and thus improve the energy security of their own countries. The existing renewable energy supply, such as wind energy, photovoltaic solar power, still requires investment and efforts, since there is still much room for upgrading. For example, the conversion rate of the latest photovoltaic cells has just reached 18\% [27], which can be improved in further research.

Another technological improvement can be achieved by developing and optimizing mixed energy system of multiple energies. In some countries, the reserves and types of renewable energy resources have obvious regional characteristics and have the inherent advantages of diversified development. Regarding the development and utilization of renewable energy, the government should further promote the diversified development of renewable energy structure, strengthen the coordination between different types of renewable energy, and then improve the comprehensive energy utilization efficiency.

In addition, data analysis and computer information technology can be integrated into the renewable energy application system to predict and optimize control of uncertain information. Referring to the energy exchange between Denmark and the Nordic countries, every nation should continue to strengthen the construction of power infrastructure and power market, study the integration and dispatch technology of renewable energy, and realize the optimal allocation and efficient use of large-scale renewable energy resources.

In the policy-making aspect, the energy market regulations have not been perfected and optimized for every renewable energy in most of countries. There is no global energy optimization strategy which leads to a problem that some developed countries have transferred carbon emission to developing countries. In this case, the global net-zero carbon emission goal is hard to achieve. Therefore, policies and regulations should be adjusted accordingly to achieve global sustainability goals.

It is suggested to improve market policies, guide benign market competition, and gradually open up domestic and foreign market transactions. A mature energy market can attract more capital to enter the market, maintain the competitiveness in the market, help to reallocate energy allocation, and accelerate the technological development. Government departments should also further strengthen the system and mechanism of the integrated energy service market to help maintain the stable operation of the market. One country must also pay attention to the guiding role of laws and regulations in the comprehensive energy service business. The local goals should be coordinated with the national strategy to ensure that identical goals are achieved. The energy resource characteristics, energy supply and consumption characteristics of each nation should be fully integrated. Furthermore, multi-dimensional and multi-level relevant policies and laws and regulations are promulgated to ensure the implementation of comprehensive energy services. In terms of energy policy and regulations, the Danish practical experience shows that the government has effectively promoted the local comprehensive energy service business through the combination of comprehensive operation goal orientation, financial incentives, laws and regulations, technology development and other policies and regulations orderly development.

\section{Conclusions}

Sustainability is a significant goal for future development and the renewable energy plays an essential role in the achievement of sustainable development.

Although many progresses have been made during the past 20 years with the efforts of all countries, there is still a far way to go before all SDGs will be finally achieved. A mixed energy system is suggested to be developed and optimized according to the characteristics of each nation in techno-economic aspect. In policy-making aspect, more efforts should be made in energy market development for new renewable energy resources. 


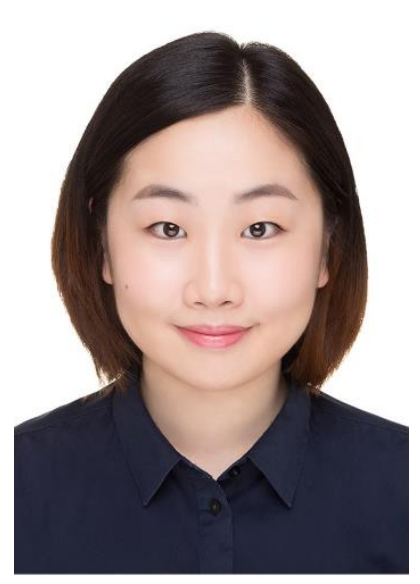

Miss Ruojue LIN is a PhD researcher in the Department of Industrial and Systems Engineering, The Hong Kong Polytechnic University, Hong Kong. Her research focuses on life cycle sustainability modelling for energy system, life cycle sustainability prioritization, sustainability optimization, engineering operations research for renewable energy and multi-criteria methods on sustainable development.

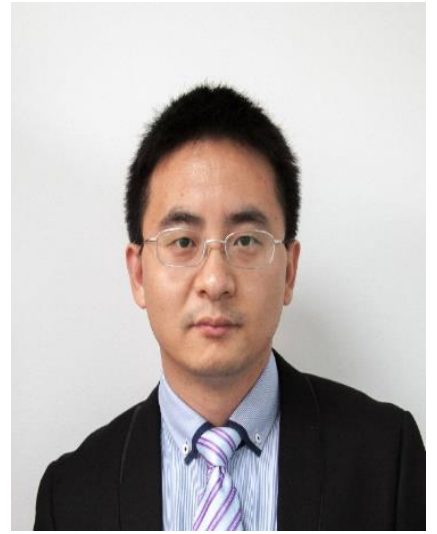

Dr. Jingzheng Ren, Assistant Professor of the Hong Kong Polytechnic University (PolyU) and Adjunct/Honorary Associate Professor of University of Southern Denmark (SDU). His research mainly focuses on Operations Management for Energy, Environment and Sustainability. He has also authored/co-authored more than140 papers in the leading refereed SCI indexed journals, published 7 edited books in Elsevier or Springer, and contributed more than 30 book chapters.

\section{Reference}

[1] A. M. H. Clayton and N. J. Radcliffe, Sustainability: A systems approach. 2018.

[2] G. M. Mace, "The limits to sustainability science: Ecological constraints or endless innovation?," PLoS Biol., 2012.

[3] P. Gazzola and E. Querci, "The Connection Between the Quality of Life and Sustainable Ecological Development," Eur. Sci. J., 2017.

[4] G. Brundtland, "WCED: Our Common Future," Oxford Pap., 1987.

[5] United Nations, "Millennium Developmenet Goals Indicators: The Official United Nations site for the MDG Indicators," Off. List MDG Indic., 2008.

[6] United Nations, "Transforming Our World: the 2030 Agenda for Sustainable Development United Nations United Nations Transforming Our World: the 2030 Agenda for Sustainable Development. A/RES/70/1," United Nations, 2015.

[7] P. A. Owusu and S. Asumadu-Sarkodie, "A review of renewable energy sources, sustainability issues and climate change mitigation," Cogent Engineering. 2016.

[8] A. Armin Razmjoo, A. Sumper, and A. Davarpanah, "Energy sustainability analysis based on SDGs for developing countries," Energy Sources, Part A Recover. Util. Environ. Eff., 2020.

[9] I. Parry, "Fossil-fuel subsidies assessed," Nature. 2018.

[10] F. Perera, "Pollution from fossil-fuel combustion is the leading environmental threat to global pediatric health and equity: Solutions exist," International Journal of Environmental Research and Public Health. 2018.

[11] M. A. Destek and A. Aslan, "Renewable and non-renewable energy consumption and economic growth in emerging economies: Evidence from bootstrap panel causality," Renew. Energy, 2017.

[12] A. Mohammadi and M. Mehrpooya, "A comprehensive review on coupling different types of electrolyzer to renewable energy sources," Energy, 2018.

[13] S. D. Cîrstea, C. Moldovan-Teselios, A. Cîrstea, A. C. Turcu, and C. P. Darab, "Evaluating renewable energy sustainability by composite index," Sustain., 2018.

[14] United Nations, "The sustainable development goals report 2019," 2019.

[15] H. E. Murdock, Renewables 2019 Global Status Report Collaborative, no. July. 2019. 
[16] P. Leyman and M. Vanhoucke, Renewable Energy Policies in a Time of Transition, vol. 53, no. 9. 2015.

[17] L. Ouyang, J. Huang, H. Wang, J. Liu, and M. Zhu, "Progress of hydrogen storage alloys for Ni-MH rechargeable power batteries in electric vehicles: A review," Materials Chemistry and Physics. 2017.

[18] R. Jia, Z. Feng, K. Tao, B. Dou, Y. Sun, and Z. Jin, "Current transportation enhancement with ZnO nanoroads for silicon nanowire solar cell," in 2017 IEEE 44th Photovoltaic Specialist Conference, PVSC 2017, 2017.

[19] L. Sai, Z. Wei, and W. Xueren, "The Development Status and Key Technologies of Solar Powered Unmanned Air Vehicle," in IOP Conference Series: Materials Science and Engineering, 2017.

[20] X. Wang et al., "Potential emission reductions by converting agricultural residue biomass to synthetic fuels for vehicles and domestic cooking in China," Particuology, 2020.

[21] G. Alva, Y. Lin, and G. Fang, "An overview of thermal energy storage systems," Energy. 2018.

[22] P. Ralon, M. Taylor, A. Ilas, H. Diaz-Bone, and K.-P. Kairies, "IRENA (2017), Electricity storage and renewables: Costs and markets to 2030," International Renewable Energy Agency, Abu Dhabi, 2017. .

[23] M. Kumar Trivedi, "Biofield Energy Signals, Energy Transmission and Neutrinos," Am. J. Mod. Phys., 2016.

[24] K. Jin and W. Zhou, "Wireless Laser Power Transmission: A Review of Recent Progress," IEEE Trans. Power Electron., 2019.

[25] P. Leyman and M. Vanhoucke, Renewable Energy Policies in a Time of Transition, vol. 53, no. 9. 2015.

[26] A. Sokolov, S. Paltsev, H. Chen, M. Haigh, R. Prinn, and E. Monier, "Climate Stabilization at $2^{\circ} \mathrm{C}$ and Net Zero Carbon Emissions," vol. 309, no. March, 2017.

[27] Y. Cui et al., "Single-Junction Organic Photovoltaic Cells with Approaching 18\% Efficiency," Adv. Mater., 2020. 